Original Research Article

\title{
Medication package inserts: how far do they adhere to the guidelines?
}

\author{
Neha Deep*, Roslin Jose, Ananya Chakraborty
}

Department of Pharmacology, Vydehi Institute of Medical Sciences and Research Centre, Bangalore 560066, Karnataka, India

Received: 25 October 2016 Accepted: 23 November 2016

*Correspondence to:

Dr. Neha Deep,

Email: 0808.neha@gmail.com

Copyright: () the author(s), publisher and licensee Medip Academy. This is an openaccess article distributed under the terms of the Creative Commons Attribution NonCommercial License, which permits unrestricted noncommercial use, distribution, and reproduction in any medium, provided the original work is properly cited

\begin{abstract}
Background: Package Insert (PI) is a document that is provided with the package of a drug. It is chiefly directed at the prescribers and is set to provide information for the safe and effective use of the respective drug. This study was conducted to assess the completeness of clinical information provided in the currently available PIs.

Methods: PIs were collected from pharmacies located at various parts of Bangalore over three months. A total of 310 drugs were checked for package inserts (PI) and 192 PI's were collected. They were analysed based on the criteria mentioned in Schedule D of Drug and Cosmetic act 1945.

Results: Out of 192 PIs, 33 were repeated and so were not taken into account. Hence, 159 PIs were analysed. Among 159 PIs, 43 (27.04\%) were of Cancer chemotherapy drugs; 19 (11.94\%) of antibiotics, 18 of anti-diabetic drugs, 13 $(8.17 \%)$ of Vitamins and minerals, $10(6.28 \%)$ of Cardiac drugs, $9(5.66 \%)$ of Respiratory drugs, $6(3.77 \%)$ of CNS drugs, 5 (3.14\%) of Ophthalmic eye solutions, $4(2.51 \%)$ of Hormones and reproductive system, $4(2.51 \%)$ of GIT, 4 $(2.51 \%)$ of Antifungals, $3(1.88 \%)$ of steroids, and $21(13.20 \%)$ of miscellaneous drugs respectively. Out of them, the PIs that belonged to "A", "B", and "C" categories were $5(3.14 \%), 150(94.33 \%)$, and $4(2.51 \%)$ respectively. It was observed that the PIs were inadequate in many aspects. Majority of the PIs had unclear instructions about drug usage, special precautions, ability to drive and use machines and adverse effects to name a few.

Conclusions: This study showed that many of the drugs now days come without PI. Also of the available ones, very few fulfil all the criteria mentioned in the guidelines. With the growing sales of over the counter drugs in India, it is important for companies to dispense PIs with all the drugs. PIs oriented toward educating the patient are the need of the hour.
\end{abstract}

Keywords: Drug information, Package insert, Prescription label

\section{INTRODUCTION}

Package Insert (PI) is a document that is provided with the package of a drug. It is also known as prescription drug label or prescribing information etc. It is chiefly directed at the prescribers and is set to provide information for the safe and effective use of the respective drug. It is a regulated document. ${ }^{1} \mathrm{~A}$ good PI is written in a language that is not promotional, false, misleading, and is evidence-based. It is updated time to time based on relevant pre-clinical and clinical information. ${ }^{2}$ From the point of view of patients, it is intended to instruct them on how and when to use a medicine and to promote an understanding of the purpose, benefits and risks of the medication prescribed. ${ }^{3}$
In India, it has been observed that healthcare professionals depend on a variety of sources like textbooks and compilations for information on drugs. ${ }^{4}$ Prescribers also depend on product information in the form of leave behind literatures provided by pharmaceutical companies. ${ }^{5}$ However, the information provided by pharmaceutical companies in India has been found to be inadequate and not in compliance with the WHO standards. Therefore, PIs are useful sources of information both for patients and healthcare providers. ${ }^{6,7}$

Package Inserts in India are governed by the 'Drugs and Cosmetics Act (1940) and Rules (1945). The section 6 of Schedule D (II) of the rules lists the headings according to which information should be provided in the PIs. The 'Section 6.2' mandates that the PIs must be in 'English' and provides information regarding the specific 
requirements. The 'Section 6.3' mandates pharmaceutical information on list of excipients.

Previous studies have pointed out that many of the available PIs in Indian market fail to adhere to the guidelines. It is evident from the studies published over the last 5 years that with time the PIs are getting better. However, the information is still not found to be complete, and as per the guidelines. Many of the PIs lack information on the ability to drive and use machines after taking the drug. This is very important for all sedative and hypnotics and other drugs which interfere with the central nervous system. Also, they contain inadequate information regarding storage, shelf life and pricing of the drug. ${ }^{7,9,10}$

With this background, this study was conducted to assess the completeness of clinical information provided in the currently available package inserts in India based on the criteria mentioned in Schedule D of Drug and Cosmetic act 1945

\section{METHODS}

\section{Collection of package inserts}

Package inserts (PIs) were collected from various pharmacies located in various parts of Bangalore on request over a period of three months, from June to August 2016.

\section{Analysis of content of package inserts}

PIs were evaluated based on criteria laid down by Indian Drug and Cosmetic Rules, 1945 under section 6.2 of schedule D. Evaluation was based on whether they contained the headings required per the Indian Drug and Cosmetic Rules criteria for 25 clinically important parameters. Data were extracted twice to minimize chances of missing any information.

\section{Criteria of package inserts}

The PIs were analysed based on the following criteria:

1. Legibility.

2. Approved generic name of active ingredients.

3. Content of active ingredient per dosage form.

4. Generic names of other ingredients.

5. Therapeutic indications.

6. Posology and method of administration.

7. Contraindications.

8. Special warnings and precautions.

9. Drug interactions.

10. Pregnancy and lactation.

11. Pediatric and geriatric indications.

12. Special conditions and contraindications.

13. Effect on ability to drive and use machines.

14. Undesirable effects.

15. Drug dose.
16. Over dosage.

17. Pharmacokinetic information.

18. Storage information.

19. Instructions for use and handling.

20. Shelf life.

21. Date on which information was last updated.

22. Name and address of the manufacturer/distributor.

23. Provision of full information on request should be highlighted.

24. Retail price of the drug.

25. References.

\section{Scoring and grading of PIs}

A total score of 25 was assigned to each. Presence of information was scored as ' 1 ' and absence was scored ' 0 '. Total score was expressed in percentages. If a package insert met more than 20 criteria, it was graded as ' $A$ ', $10-20$ criteria as ' $B$ ' and less than 10 as ' $C$ '.

\section{RESULTS}

Table 1: Package inserts that followed criteria lay down by Drug and Cosmetic Rules, 1945.

\begin{tabular}{|lll|}
\hline Criteria & Mentioned & $\begin{array}{l}\text { Not } \\
\text { mentioned }\end{array}$ \\
\hline Legibility & $85 \%$ & $15 \%$ \\
\hline Generic name & $99 \%$ & $1 \%$ \\
\hline Active ingredients & $98 \%$ & $2 \%$ \\
\hline $\begin{array}{l}\text { Generic name of other } \\
\text { ingredients }\end{array}$ & $97 \%$ & $3 \%$ \\
\hline Indication & $99 \%$ & $1 \%$ \\
\hline Method of administration & $93 \%$ & $7 \%$ \\
\hline Contraindications & $92 \%$ & $8 \%$ \\
\hline Warning and precautions & $96 \%$ & $4 \%$ \\
\hline Interactions & $86 \%$ & $14 \%$ \\
\hline Pregnancy and lactation & $83 \%$ & $17 \%$ \\
\hline $\begin{array}{l}\text { Paediatric and geriatric } \\
\text { indication }\end{array}$ & $61 \%$ & $39 \%$ \\
\hline $\begin{array}{l}\text { Ability to drive and use } \\
\text { machines }\end{array}$ & $19 \%$ & $81 \%$ \\
\hline Undesirable effects & $95 \%$ & $5 \%$ \\
\hline Dose & $97 \%$ & $3 \%$ \\
\hline $\begin{array}{l}\text { Pharmacokinetic } \\
\text { information }\end{array}$ & $81 \%$ & $19 \%$ \\
\hline Storage & $88 \%$ & $12 \%$ \\
\hline $\begin{array}{l}\text { Instruction for use and } \\
\text { handling }\end{array}$ & $42 \%$ & $58 \%$ \\
\hline Shelf life & $24 \%$ & $76 \%$ \\
\hline Info updated & $24 \%$ & $76 \%$ \\
\hline $\begin{array}{l}\text { Name and address of } \\
\text { manufacturer }\end{array}$ & $88 \%$ & $12 \%$ \\
\hline Info on request & $11 \%$ & $89 \%$ \\
\hline Retail price & $11 \%$ & $89 \%$ \\
\hline References & & $100 \%$ \\
\hline
\end{tabular}

A total of 310 drugs were checked for package inserts 
(PI). Out of them, only $192(61.93 \%)$ drug boxes were with PIs. Other $118(38.06 \%)$ drugs were without PIs. Out of 192 PI's, 33 (17.18\%) were repeated and were not considered for the study. A total of 159 PIs were analyzed. The evaluation results are shown in Table 1.

Out of 159 PIs, $130(81.76 \%)$ were from Indian companies and $29(18.23 \%)$ from multinational companies (Figure 1). Also, the number of PIs of oral, injectable, and topical were 93 (58.49\%) 57 (35.84\%), and $9(5.66 \%)$ respectively. The PIs that belonged to "A", "B", and "C" categories were 5 (3.14\%), 150 (94.33\%), and $4(2.51 \%)$ respectively (Figure 2$)$.

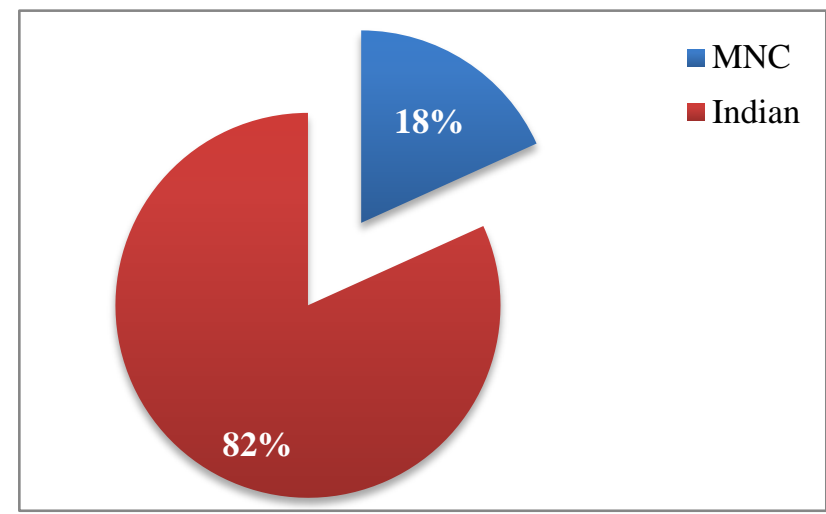

Figure 1: Percentage of package inserts by Indian and Multinational Companies.

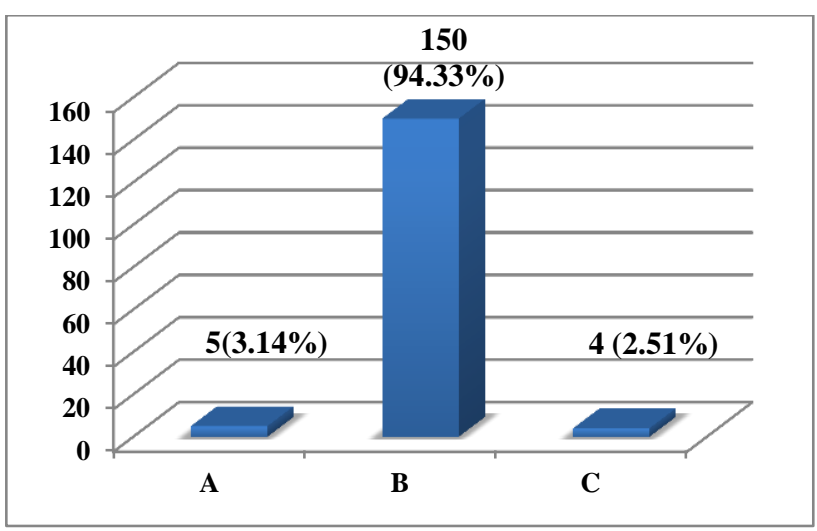

A: Adherence to $>20$ criteria

B: Adherence to $10-20$ criteria

C: Adherence to $<10$ criteria

\section{Figure 2: Grades of package inserts}

Among 159 PIs, 43 (27.04\%) were of Cancer chemotherapy drugs; 19 (11.94\%) of antibiotics, 18 of anti-diabetic drugs, $13(8.17 \%)$ of Vitamins and minerals, $10(6.28 \%)$ of Cardiac drugs, $9(5.66 \%)$ of Respiratory drugs, $6(3.77 \%)$ of CNS drugs, $5(3.14 \%)$ of Ophthalmic eye solutions, $4(2.51 \%)$ of Hormones and reproductive system, $4(2.51 \%)$ of GIT, $4(2.51 \%)$ of Antifungals, 3 $(1.88 \%)$ of steroids, and $21(13.20 \%)$ of miscellaneous drugs respectively (Figure 3 ).

Out of the $43(27.04 \%)$ PIs of Cancer chemotherapy drugs; 36 (83.72\%) were from Indian companies and 7 (16.27\%) from multinational companies. All the PIs were of injectable preparations. $42(97.67 \%)$ belonged to category "B" and $1(2.32 \%)$ belonged to category " $\mathrm{C}$ ". None of the PIs belonged to category A.

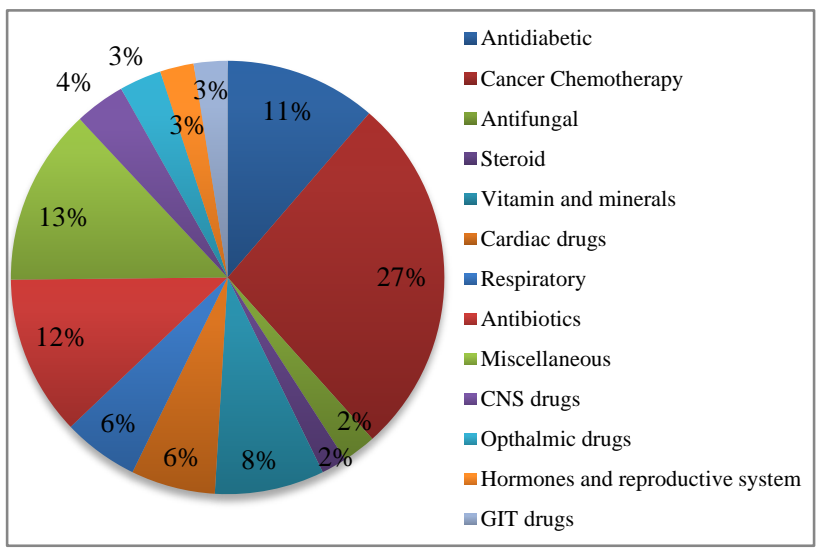

Figure 3: Percentage of various classes of package inserts $(n=159)$.

Among 19 (11.94\%) PIs of antibiotics, 17 (89.47\%) were of oral antibiotics and $2(10.52 \%)$ were of injectable antibiotics. All PIs belonged to "B" category.

18 PIs were of anti-diabetic drugs. Out of these 14 $(77.77 \%)$ were of oral preparations and $4(22.22 \%)$ were of injectable preparations. All PIs of anti-diabetic drugs belong to the "B" category.

\section{DISCUSSION}

In this study, PIs of various drugs were evaluated to see if they contained information according to Indian Regulatory Guidelines. It was observed that the PIs were inadequate in many aspects. The presentation, font size, and color were appropriate only in $85 \%$ of the PIs. Some PIs were not readable at all. Small font size was a common problem. Similar observation was made in previous studies. If PIs are unread they have potential educational and legal implications. ${ }^{11,12}$

Out of the 159 PIs, only 5 belonged to "A" category, 150 belonged to " $\mathrm{B}$ " category and 4 belonged to " $\mathrm{C}$ " category. Contrary to the previous studies in which none of the PIs belonged to the "C" category."

Indications for use were present in all the inserts (100\%) and information on posology, side effects, special warnings, drug interactions, and contraindications were mentioned in at least $80 \%$ of the package inserts studied which is similar to previous studies. ${ }^{13}$ Generic name of the drug was present in $99 \%$ of the PIs. Generic names of other ingredients and active ingredients were present in $99 \%$ and $98 \%$ of the PIs respectively. Also, information about use in pregnancy and lactation, pediatric and geriatric indications and undesirable effects were present 
in $83 \%, 61 \%$ and $95 \%$ PIs respectively. Again, storage information was adequate in $88 \%$, instructions for use and handling in $42 \%$ and date on which information was last updated in $24 \%$ of PIs. Information about shelf life was present in $24 \%$ and references were present in $11 \%$. However, retail price of the drug was not present in any of the PI, which is similar to the observations made in previous studies. ${ }^{14}$

Information about the effect on ability to drive and use of machines was present only in $19 \%$ of the PIs and were absent in $81 \%$ of PIs. Many of the drugs which have sedative action or which interfere with the CNS function didn't mention anything about driving or using machines after taking these drugs. This is a big fallacy at the end of the pharmaceutical companies. Since such drugs can lead to impaired judgment, reaction time, motor skills and memory, prior information will be beneficial to the patient.

In this study, it was found that many drugs come without a package insert. This is a major cause of concern in the healthcare sector. In countries like India, there is an inadequate doctor patient ratio. Accessibility to trained prescribers is difficult and physicians are not able to spend enough time with their patients. This gives rise to self-medication, medication errors and adverse drug reactions. All these issues indicate the PI, should be more patient oriented and provide the correct, concise and adequate information to its users. ${ }^{15}$

Today the government and the fraternity are concerned about proper eco-friendly disposition of left over medications. Regulatory authority can take this into account and can consider including them in the PIs.

\section{CONCLUSION}

Package insert PI play an important role in disseminating first-hand knowledge about the drug to the patient. This study showed that many PI of the drugs now days come without a package insert. Of the available PIs very few fulfil all the criteria mentioned in the guidelines. With the growing sales of over the counter drugs in India, it is important for companies to dispense PIs with all the drugs. PIs oriented toward educating the patient are the need of the hour.

Funding: No funding sources Conflict of interest: None declared

Ethical approval: The study was approved by the Institutional Ethics Committee

\section{REFERENCES}

1. Anonymous. An Introduction to the Improved FDA Prescription Drug Labeling. CDER Learn. 2009. Available from: http://www.fda.gov/Training/ForHealthProfessionals/ ucm090590.htm Accessed on 10th September 2016

2. Ved JK. Package Inserts in India: Need for a Revision. International Journal of Pharmaceutical Sciences and Research. 2010;1(11):454-56.

3. Sinaa A Al-aqeel. Evaluation of medication package inserts in Saudi Arabia. Drug, Healthcare and Patient Safety. 2012;4:33-8.

4. Rajan MS, Sreedhar, Khan SA, Thiyagu R, Rao PG. Information seeking behaviour of clinicians in a semi urban town in southern India. Journal of Clinical and Diagnostic Research. 2008;2:1069-73.

5. Prosser H, Almond S, Walley T. Influences on GPs' decision to prescribe new drugs-the importance of who says what. Fam Pract. 2003;20:61-8.

6. Dikshit RK, Dikshit ND. What information is available on request from drug advertisers. BMJ. 1996;313:855-6.

7. Lal A, Sethi A. Drug package inserts in India. Ann Pharmacother. 1996;30:1041.

8. The Drugs and Cosmetics Act and Rules. Ministry of Health and Family Welfare, Government of India. 2003. p. 312. Available from: http://cdsco.nic.in Accessed on March 15th, 2013.

9. Ramdas D, Chakraborty A, Swaroop HS, Faizan S, Kumar PV, Srinivas BN. A Study Of Package Inserts In Southern India. Journal of Clinical and Diagnostic Research. 2013:11;2475-7.

10. Shivkar YM. Clinical information in drug package inserts in India. J. Postgrad. Med. 2009;55(2):104-7.

11. Bansal V, Dhamija P, Medhi B, Pandhi P. Package inserts-do they have any role? JK-Practitioner. 2006;13(3):152-4.

12. Joubert P, Lasagna L. Patient package inserts: nature, notions and needs. Clin Pharmacol Ther. 1975;18:507-13.

13. Solanki SN, Chhaiya SB, Mehta DS, Trivedi M, Acharya T, Patel D. Analytical evaluation of drug package inserts in India. International Journal of Basic and Clinical Pharmacology. 2015;4:322-4.

14. Sudhamadhuri A, Kalasker V. Evaluation of Completeness of Package Inserts in South India. International Journal of Research Studies in Biosciences. 2015;3(7):102-10.

15. Morris LA, Patients package inserts: A new tool for Patient education Public Health Reports. 1997;92(5):421-24.

Cite this article as: Neha D, Jose R, Chakraborty A. Medication package inserts: how far do they adhere to the guidelines?. Int J Basic Clin Pharmacol 2017;6:133-6. 